\title{
A importância da epistemologia na Teoria do Jornalismo: a teoria pragmática do conhecimento e a qualidade da notícia
}

\author{
HeItor Costa Lima da Rocha \\ Universidade Federal de Pernambuco - heitor@nlink.com.br \\ Professor do Grupo de Pesquisa Jornalismo e Contemporaneidade do \\ Programa de Pós-Graduação em Comunicação (PPGCOM).
}

\begin{abstract}
Resumo
Este trabalho pretende discutir a importância da epistemologia na consolidação do campo de estudos em jornalismo e, conseqüentemente, na valorização desta prática social, procurando conferir contornos mais claros à concepção do conhecimento possível nesta área. Com este intuito, são cotejadas reflexões sobre o conhecimento no campo específico do jornalismo e a teoria pragmática universal de Jürgen Habermas, no tocante ao processo de aprendizagem do conhecimento e ao seu papel na construção do consenso social. Assim, pretende distinguir as implicações epistemológicas da comunicação não só para a reprodução da ordem social estabelecida, mas sobretudo para a transformação social, através de um jornalismo de qualidade, referenciado num acervo de excelência profissional crítico e inclusivo com a capacidade de ampliar a sua legitimidade e a representatividade do consenso social.
\end{abstract}

Palavras-chave

Teorias do jornalismo, notícia e conhecimento, epistemologia.

\begin{abstract}
This work discusses the importance of epistemology on the consolidation of journalism studies and the valorization of this social practice. It looks forward to make clear what kind of knowledge is possible in this area. It is based on reflections about knowledge in the journalism field and Jürgen Habermas' universal pragmatics, specially the learning process and it's role in construction of the social consensus. It's objective is to distinguish the epistemological implications of communication not only for the reproduction of the established social order, but above all for social transformation through quality journalism based on a heritage of critical and inclusive profissional excelence capable of increasing it's legitimacy and the representativity of the social consensus.
\end{abstract}

\section{Keywords}

Theories of journalism, news and knowledge, epistemology.

Artigo recebido em 05/10/2010

Aprovado em 10/12/2010 


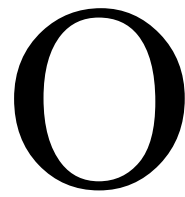

crescente reconhecimento do papel central e estratégico do jornalismo na sociedade contemporânea reveste de um caráter especial a necessidade de consolidação deste campo de estudo específico diante do constante desafio que o jornalista enfrenta de conquistar credibilidade e legitimação para o sentido do consenso que articula como fator imprescindível para desenvolvimento do processo civilizatório, em face das ameaças anômicas que esgarçam o contrato e a coesão sociais com a elevação dos potenciais de conflito e violência.

Contrariando uma tendência, infelizmente, ainda muito forte de menosprezo pela teoria e de absolutização da prática, se pode constatar a complexidade intelectual envolvida no ofício de selecionar e codificar as notícias, com o reconhecimento das implicações epistemológicas e metodológicas que não podem ser dissociadas das tarefas mais elementares deste ofício de atualizar as referências com que os cidadãos embasam seus posicionamentos na vida cotidiana.

Com este propósito, o presente trabalho aborda a discussão sobre 0 conhecimento no jornalismo relacionando a distinção entre ciência e senso comum e a função que desempenham na sociedade; a questão epistemológica do deslocamento da teoria da verdade como correspondência entre enunciado e realidade para uma teoria consensual da verdade fundamentada na teoria pragmática do conhecimento e do processo de aprendizagem de Jürgen Habermas; e, por fim, as implicações epistemológicas e metodológicas na prática jornalística, a partir de concepções de autores como Teun Van Dijk (2005), Eduardo Meditsch (2007), Miquel Rodrigo Alsina (2009) e Daniel Hallin (1994).

\section{O conhecimento no jornalismo}

A necessidade de aprofundamento da discussão epistemológica sobre o conhecimento envolvido na produção jornalística e proporcionado ao seu público vem sendo colocado por destacados autores desta área como grande desafio para consolidação do reconhecimento do jornalismo como atividade estratégica na sociedade contemporânea, também denominada de sociedade midiatizada. 
De forma pioneira, Robert Park (2008, p. 52-55), com inspiração pragmática, utiliza os conceitos de William James - aqcuaintance with, conhecimento adquirido dos usos e costumes, e knowledge about, conhecimento formal e sistemático com estatuto de ciência - para afirmar que estes tipos de conhecimento formam um continuum em que os outros tipos de conhecimento, como o construído nas notícias, se localizam.

Em tal continuum a notícia tem localização própria. É óbvio que a notícia não é conhecimento sistemático como aquele das ciências físicas. Trata de eventos. Eventos são únicos e, portanto, não podem ser classificados como acontece com as coisas, porque eles são invariavelmente fixos no tempo e localizados no espaço (PARK, 2008, p. 58).

Para Teun Van Dijk (2005), porém, a discussão sobre o conhecimento no jornalismo tem sido pouco explorada, a despeito da trivialidade da evidência de que não haveria notícia sem algum conhecimento que permitisse aos jornalistas escreverem as suas matérias.

O estudo do conhecimento nas notícias é vital para o entendimento de muitos aspectos fundamentais da produção e compreensão noticiosa. (...) os jornalistas dificilmente podem produzir notícias sem algum tipo de conhecimento "do mundo", e especialmente de novo conhecimento do mundo. Esta consideração bastante óbvia, no entanto, levanta muitas questões complexas (VAN DIJK, 2005, p. 14).

Entre estas questões complexas, o autor holandês cita a compreensão de como se dá a aquisição do conhecimento prévio do mundo necessário à elaboração das notícias, a sua natureza e como ele se reflete nas estruturas das matérias jornalísticas. As coisas e estados de coisas do mundo nos são inteligíveis na medida em que nossa estrutura cognitiva pode lhes compreender como algo que se acrescenta ao nosso acervo de conhecimentos, modificando-o, ou até vir a revolucionar a nossa visão de mundo, desde que a partir das referências preexistentes na nossa estrutura de referências, de sentidos.

$\mathrm{Na}$ sua tipologia do conhecimento, Van Dijk (2005) explicita, em ordem gradativa de ampliação de seu âmbito de compartilhamento, o conhecimento pessoal, o conhecimento interpessoal, o conhecimento grupal/social e o conhecimento cultural, cuja disseminação mais generalizada fica a cargo da mídia.

No processo de codificação e decodificação das informações contidas nas notícias, Teun Van DIJK (2005) registra a variação de pessoa para pessoa e até de 
momento do leitor no investimento para apreensão do texto; a monitoração para atualização do próprio acervo de conhecimentos e o dos receptores; a ordem processual das informações na estrutura da notícia; a construção de modelo contextual; o reconhecimento do gênero; a identificação do tópico e estabelecimento de coerência global; a interpretação das palavras e das sentenças; estabelecimento da coerência local; a estrutura aparente para decodificação de formas; e a compreensão para formação ou atualização de modelos mentais na estrutura cognitiva registrada na memória.

Depois de observar que termos como "conhecimento do mundo" e "base compartilhada" são atualmente pouco detalhados nas diversas disciplinas ligadas ao tema, Teun Van Dijk (2005, p. 19) salienta que, além disso, a circulação destes conhecimentos é restrita, pois "grupos específicos, tais como acadêmicos ou outros especialistas, podem ter conhecimento que compartilham com membros do seu grupo, mas que fora desse grupo é desconhecido ou só parcialmente conhecido". Ao contrário das demais instituições com suas linguagens especializadas, que pretendem restringir a sua comunicação aos iniciados de seu subuniverso de significação (BERGER; LUICKMANN, 1995), do Jornalismo espera-se exatamente atingir o maior número possível de cidadãos, tendo como auditório ideal a sociedade como um todo.

Pode-se identificar nas redes de peritos técnico-científicos uma linguagem cuja universalidade é apenas formal, devido ao fato de se caracterizar por uma espécie de “incomunicação" entre os dialetos das diversas especialidades.

Já o ideal de universalidade do jornalismo caminha em outra direção. $\mathrm{O}$ auditório universal que idealmente persegue se refere a uma outra rede de circulação de conhecimento, constituída pela comunicação para devolver à realidade a sua transparência coletiva. É uma universalidade de fato, embora precária, porque é estabelecida institucionalmente de forma indireta e imperfeita, tal e qual o espaço público pressuposto pelo ideal democrático que a precede e a requer. A sua amplitude é também limitada em outra direção, a intenção do emissor na delimitação do universo do público-alvo. Mas é na preservação deste auditório ideal que o jornalismo encontra uma de suas principais justificações sociais: a de manter a comunicatibilidade entre o físico, o advogado, o operário e o filósofo (MEDITSCH, 2007, p. 282).

Além do posicionamento quanto à circulação do conhecimento de Teun Van Dijk, também Eduardo Meditsch encontra evidencias na sociologia e na antropologia do 
conhecimento que levam à idéia de que, de acordo com os auditórios a que se dirigem os diversos discursos, a questão do saber na sociedade se torna mais complexa. Neste contexto, a metodologia científica, além de não ser a única forma de conhecer, provavelmente, pode "nem sequer ser a mais importante para a nossa sobrevivência individual e de nossa existência gregária” (MEDITSCH, 2007, p. 279).

Para superação da presunção cientificista do positivismo, que respalda a teoria do espelho e o menosprezo pelo conhecimento processado no jornalismo pelo senso comum, é auspiciosa a reflexão de Boaventura de Souza Santos sobre a ciência e o senso comum. Para ele, a ciência moderna distinguiu-se desqualificando o senso comum como falso, ilusório e superficial, mas, com isso, desprezou algumas virtualidades dessa forma de conhecimento (visão de mundo pragmática assente na ação e no princípio da criatividade e da responsabilidade individuais, bem como compromissada com a transparência e o princípio da igualdade de acesso ao discurso e às competências cognitivas e lingüística), que podem enriquecer a sua relação com o mundo, com a distinção utópica e libertadora que pode ser potencializada através do diálogo com o pensamento científico.

$\mathrm{Na}$ ciência moderna a ruptura epistemológica simboliza o salto qualitativo do conhecimento do senso comum para o conhecimento científico; na ciência pós-moderna o salto mais importante é o que é dado do conhecimento científico para o conhecimento do senso comum. O conhecimento científico pós-moderno só se realiza enquanto tal na medida em que se converte em senso comum (SANTOS, 2000, p. 57).

O senso comum constitui-se numa atitude cognitiva classificada como natural precisamente porque vislumbra um mundo que é comum a muitos homens, partilhado nas rotinas normais e tido como auto-evidente na vida cotidiana, erigindo uma certa percepção da realidade como dominante (MEDITSCH, 2007, p. 281).

A formação dos conhecimentos que estruturam o senso comum, desta maneira, não se dá de maneira igualitária e democrática como se poderia imaginar a partir do termo. Antes é conseqüência de uma desigual distribuição social do conhecimento (BERGER E LUCKMANN, 1995). Neste sentido, Eduardo Meditsch observa que a repartição social do conhecimento resulta na formação de sistemas de perícia extraordinariamente complexos. Para ele, "a distribuição social do conhecimento, desta 
forma, não se dá apenas em termos quantitativos (uns conhecem mais do que outros), mas também qualitativos (conhecem coisas diferentes)" (MEDITSCH, 2007, p. 282).

O papel desempenhado pelo jornalismo não é exclusivamente positivo como vislumbrado na sua face positiva de fortalecer o sentido do consenso social e contribuir para a evolução do processo civilizatório. Por outro lado, o conhecimento produzido pelos jornalistas também apresenta limitações lógicas decorrentes não só dos condicionamentos culturais históricos, mas também dos problemas estruturais de sua configuração industrial.

A presunção positivista contida na teoria da verdade como correspondência entre enunciado e realidade viabiliza a dissimulação desses condicionamentos e a mitificação da apresentação da notícia como sendo a própria realidade (teoria do espelho).

A falta de referências epistemológicas consistentes, como as de uma teoria pragmática do conhecimento, certamente dificulta o desempenho excelente do jornalista para a construção de uma notícia de qualidade. Sem um instrumental teórico que fundamente adequadamente a sua prática profissional, o jornalista fica sem defesas para enfrentar condicionamentos como as pressões econômicas pela espetacularização. $\mathrm{O}$ compromisso de buscar conferir maior representatividade e legitimidade ao produto jornalístico implica no respeito ao discernimento intersubjetivo de seus auditórios, descartando, evidentemente, a apresentação da notícia como se fosse a própria realidade. Devido à complexidade da prática jornalística, conforme adverte Meditsch (2007, p. 286), é muito difícil distinguir entre os objetivos cognitivo, que é transparente, e os econômico e político, cuja possibilidade de êxito exige, muitas vezes, que sejam dissimulados.

Neste sentido, chama atenção o fato de que grande parte dos pecados atribuídos ao jornalismo ter origem em outros campos. A distorção sistemática da comunicação que compromete o sistema democrático, a crescente desigualdade social, a manipulação e disseminação dos preconceitos e estereótipos do discurso ideológico dominante não são criações do jornalismo, embora tudo isso faça parte da realidade com que trabalha. "Como produto social, o jornalismo reproduz a sociedade em que está inserido, suas desigualdades e suas contradições. Nenhum modo de conhecimento disponível está completamente imune a isto" (MEDITSCH, 2007, p. 286) 
O reconhecimento da importância do conhecimento no jornalismo representa um avanço na cobrança por seus conteúdos, rigor nos seus procedimentos e exigência de formação profissional. Desta constatação, Meditsch (2007, p. 287) destaca que "a questão do conhecimento que o jornalismo produz e reproduz e dos seus efeitos pode ser demasiado estratégica para a vida de uma sociedade para ser controlada exclusivamente pelos jornalistas como grupo profissional ou pelas organizações onde trabalham".

Neste sentido, Alfredo Vizeu Pereira Jr. $(2001,127)$ considera necessário que

As instituições jornalísticas que ocupam um lugar central no desenvolvimento do capitalismo brasileiro devem estar em constante vigilância pela sociedade, uma vez que cumprem uma função relevante na construção da realidade. Logo revelar os modos de elaboração da sua matéria é contribuir não só para a reflexão da atividade jornalística, mas para o próprio aperfeiçoamento democrático dessa sociedade (PEREIRA JR, 2001, p. 127).

Após registrar a existência de várias interpretações sobre o jornalismo enquanto conhecimento, Eduardo Meditsch (2007, p. 276) considera o cientificismo positivista como um fator explicativo para o menosprezo nesta área. Para superação desta estigmatização, contribuíram, além da tradição pragmática clássica, outras correntes teóricas críticas.

As epistemologias críticas, que nas últimas décadas têm se dedicado a desmistificar o preceito positivista da infalibilidade da Ciência e a demonstrar o caráter cultural e histórico de toda a forma de conhecimento, contribuíram para destruir o ideal de uma verdade única e obrigatória e, principalmente, para estabelecer os limites lógicos de qualquer reivindicação de objetividade. Ao relativizarem as verdades científicas, estas correntes críticas permitiram também a aceitação de outras verdades como eventualmente válidas e relativas, de acordo com os seus pressupostos e objetivos. (MEDITSCH, 2007, p. 278)

Estes elementos epistemológicos podem ser identificados nas característicaschave do novo paradigma científico construtivista: rejeição do conhecimento que se pretende auto-validar e da idéia de que nossas visões de mundo revelam, sem problemas, a sua natureza autêntica; adoção da concepção de que a compreensão do mundo é histórica e culturalmente específica e relativa, sendo determinada pelos processos sociais; e assunção do compromisso de investigar como os conhecimentos 
(construção das identidades sociais, dos fenômenos e problemas) estão ligados às ações dos atores sociais.

\section{A epistemologia e as teorias da verdade e da aprendizagem}

Nesta perspectiva epistemológica, Jürgen Habermas (2004b, p. 16) concebe uma teoria do conhecimento pós-empirista, que superou a teoria da verdade como correspondência entre a representação e a realidade, formulando uma teoria consensual da verdade, iniciada por Thomas Kuhn (2007) e continuada por Richard Rorty (1998).

$\mathrm{Na}$ escolha de um paradigma, - como nas revoluções políticas - não existe critério superior ao consentimento da comunidade relevante. Para descobrir como as revoluções científicas são produzidas, teremos, portanto, que examinar não apenas o impacto da natureza e da lógica, mas igualmente as técnicas de argumentação persuasiva que são eficazes no interior dos grupos muito especiais que constituem a comunidade dos cientistas (KUHN, 2007, p. 128).

Portanto, Thomas Kuhn, pesquisador da área das ciências da natureza, argumenta, de forma contundente, em favor da imprescindível importância do processo intersubjetivo de legitimação, que só a integração na comunidade dos investigadores científicos pode propiciar.

A explicitação do contextualismo de Richard Rorty (1998, p. 19) pode ser resumida na afirmação de que "o único critério que temos para aplicar à palavra 'verdadeiro' é a justificação, e a justificação é sempre relativa a uma audiência - aos propósitos que tal audiência quer consumar e à situação na qual ela se encontra". Desta forma, não há nenhuma objetividade mitificada que possa legitimar o sentido produzido nas matérias jornalísticas senão aquilo que é considerado racionalmente válido pelo contexto de seu público, o auditório a que se dirige.

No mesmo sentido, Miquel Rodrigo Alsina (2009, p. 116) salienta que os acontecimentos sociais são definidos, em diferentes épocas, pela mídia como aqueles acontecimentos que têm transcendência social, ou seja, preenchem os parâmetros de 
conhecimento da realidade determinados pela formação política e cultural de um momento histórico da sociedade.

Isto se coaduna com a perspectiva da filosofia transcendental, que não se refere substancialmente aos objetos, mas à maneira como os conhecemos, procurando reconstruir as condições gerais e necessárias capazes de torná-los passíveis de experiência e conhecimento. Este questionamento transcendental pode ser generalizado quando concebido além do âmbito da categoria mentalista de auto-reflexão do indivíduo isolado e aplicado ao processo intersubjetivo de construção de conhecimento para solucionar problemas práticos na vida cotidiana. Segundo Habermas, com a deflação pragmática do idealismo kantiano, a análise transcendental passa a representar a busca das condições supostamente universais, ou seja, apenas, na realidade, inevitáveis para que os cidadãos possam desempenhar determinadas práticas e operações fundamentais na vida social.

\begin{abstract}
A investigação volta-se muito mais para as estruturas profundas do pano de fundo do mundo da vida, estruturas que se corporificam nas práticas e operações de sujeitos capazes de falar e agir. A análise transcendental procura os traços invariáveis recorrentes na diversidade histórica das formas de vida socioculturais. (...) Visto que o conceito da experiência é compreendido pragmaticamente, o conhecimento é considerado uma função de processos de aprendizagem, para os quais o conjunto das práticas do mundo da vida fornece sua contribuição. Disso resulta uma arquitetônica de mundo da vida e mundo objetivo, à qual corresponde um dualismo metodológico de compreensão e observação (HABERMAS, 2004b, p. 19).
\end{abstract}

Este dualismo metodológico fundamenta-se na distinção de posturas epistêmica, adequada à observação do mundo objetivo, e de compressão dos valores e normas morais vigentes no mundo social. Indagado a respeito, ele respondeu:

Sim, sou um realista nas questões epistêmicas e um construtivista nas questões morais. Sou um realista de um tipo específico, um realista segundo o viés pragmático. Estou convicto de que, na prática, não podemos senão nos opor a um mundo objetivo feito de entidades independentes da descrição que fazemos delas; um mundo que é mais ou menos o mesmo para todos (HABERMAS, 2004a, p. 46-47).

Com estas ressalvas ao positivismo e ao contextualismo, ficam aplacados os receios de alguns autores, como Orlando Tambosi (2005) e Daniel Cornu (1999), de descartarem a teoria da verdade como correspondência, mesmo em face das suas 
limitações lógicas, para não incorrer na relativização absoluta da verdade - a perda da posição realista de pressupor a existência da verdade de um mundo que existe independentemente de nossas interpretações. Não adotar a teoria da verdade como correspondência levaria os jornalistas ao "vale tudo" de negar a função normativa da moral, prevalecendo a lei do mais forte, já que verdade e razão não teriam mais possibilidade de universalidade e seriam apenas expressão de interesses poderosos.

A chave para compreensão adequada do dualismo metodológico é o processo de aprendizagem sobre a experiência, que deve ser analisado na perspectiva de um ator inserido no seu contexto social, colocando à prova os enunciados empíricos. Portanto, a objetividade de uma experiência não se mede mais pela história de sua origem na mente do sujeito (mentalismo). Pelo contrário, o esforço para solucionar construtivamente os problemas decorrentes de uma perturbação nas práticas habitualizadas - decepções performativamente vivenciadas - implica necessariamente em modificações no sistema de convicções que carecem de legitimação intersubjetiva.

A aprendizagem, então, fica condicionada à apreciação das pretensões de verdade pelos interlocutores e à resistência da realidade, tematizando as convicções com as objeções dos outros numa relação vertical com o mundo objetivo e horizontal com os demais jurisconsortes - sujeitos de uma comunidade de direitos e deveres - de um mundo da vida intersubjetivamente partilhado.

Assim, enquanto na epistemologia pragmática o processo do conhecimento é representado como um comportamento inteligente que resolve problemas e possibilita processos de aprendizagem, corrige erros e invalida objeções, na epistemologia positivista se tem a presunção enganadora de elaborar uma imagem perfeita de objetos. Para ele, o "espelho da natureza" - a representação da realidade - configura um modelo falso do conhecimento, "porque a relação de dois termos de imagem e objeto retratado e a relação estática entre enunciado e estado de coisas - faz abstração da dinâmica do crescimento do saber pela solução de problemas e pela justificação". (HABERMAS, 2004b, p. 34)

Garante o filósogo alemão que somente na perspectiva do dualismo metodológico, que entrelaça construção e experiência, se pode compreender nosso falibilismo, pois “apenas a contribuição construtiva de nossas operações para o saber 
explica por que a ampliação do saber deve passar pela eclusa da revisão permanente do saber existente e por que um saber bem fundamentado também pode ser falso" (HABERMAS, 2004b, p. 41).

A distinção entre ação e discurso também é imprescindível no modelo habermasiano para compreensão do funcionamento das crenças nestas duas dimensões da vida humana. No âmbito da ação, as práticas do mundo da vida são mantidas por uma consciência plena de certezas que não permite reservas quanto à verdade. A busca pela solução de problemas processa as decepções que surgem contra o pano de fundo de expectativas estáveis, no contexto de uma massa de concepções ingenuamente tidas por verdadeiras. No desempenho de seus papéis cotidianos num mundo objetivo concebido como idêntico e independente, os atores não podem prescindir de certezas de ação. Estas exigem que se compreendam as opiniões que governam a ação como absolutamente verdadeiras.

O conjunto dos acontecimentos construídos pela mídia como tendo transcendência social compõem um lugar de referência para orientar a compreensão da realidade das pessoas e a sua ação no mundo. Por isso, precisam ser acreditados como verdadeiros. Mas o discurso jornalístico precisa ser assumido como falível para pretender a sua excelência, ou seja, a sua constante legitimação como válido, verdadeiro e correto junto ao seu auditório, visto que as pessoas que compõem o seu público são seres em processo que estão, mais ou menos, sempre ampliando seu conhecimento sobre o mundo.

Do ponto de vista de práticas malsucedidas e certezas de ação abaladas, as argumentações divulgadas pela mídia procuram ter uma espécie de função reparadora. Isto explica por que os participantes da argumentação reconhecem não ter motivos para manter a atitude reflexiva, após o esgotamento de todas as objeções apresentadas, e se convencem da legitimidade de uma pretensão de verdade, compreendendo esta bemsucedida desproblematização da discussão sobre a verdade como um sinal para retomar uma postura ingênua diante do mundo (HABERMAS, 2004b, p. 50).

As pretensões de correção normativa dos valores e normas morais do mundo social - que formam a grande maioria das matérias jornalísticas -, no entanto, implicam um processo de legitimação com características próprias e distintas do das pretensões de 
verdade do mundo objetivo - os acontecimentos da natureza. A validade de uma norma consiste no fato de merecer reconhecimento fundamentado discursivamente. Uma norma em vigor obtém reconhecimento porque e na medida em que seria aceita, ou seja, reconhecida como válida nas condições (aproximativamente) ideais de justificação, merecendo ser identificada como de transcendência social. Não basta para uma norma moral o reconhecimento de sua existência para garantir a sua aceitação racional. É preciso que ela seja considerada correta. Um jornalismo não comprometido com este questionamento de correção normativa não consegue superar o que está convencionado, a "teia de facticidade" que reproduz a realidade existente e esvazia de sentido a integração social.

No lugar da resistência dos objetos, nos quais nos deparamos no mundo da vida, o jornalismo deve expor nas controvérsias o embate dos adversários sociais, cujas orientações axiológicas entram em conflito. No entanto, para que as pretensões de validade moral articuladas pelo jornalismo atinjam a força de um reconhecimento de legitimidade análoga à verdade, é preciso que se oriente por uma expansão constante dos pontos de vista de setores sociais excluídos na discussão pública, para que possa ser compensada a ausência da referência ao mundo objetivo (HABERMAS, 2004b, p. 53).

\section{As implicações dos posicionamentos epistemológicos e metodológicos na prática jornalística}

As concepções de mundos "real", de referência e possível de Miquel Rodrigo Alsina (2009); de esferas do consenso, da controvérsia legítima e do desvio no jornalismo de Daniel Hallin (apud TRAQUINA, 2002); e de modelos de acesso interno, de mobilização e de iniciativa externa às deliberações públicas articuladas no espaço jornalístico de Habermas (1997) oferecem parâmetros para uma aplicação empírica dos conceitos humanizados de uma teoria consensual da verdade e de uma teoria pragmática do conhecimento e da aprendizagem capaz de esclarecer o papel social do jornalismo e servir como referência para uma prática do ofício jornalístico conseqüente com o seu significado histórico.

O modelo de Alsina (2009, p. 299) descarta categoricamente a concepção da teoria do espelho ao explicitar o processo de construção da notícia como uma 
aproximação da realidade, jamais a sua reprodução perfeita como um espelho. Para ele, "a notícia é uma representação social da realidade cotidiana, produzida institucionalmente e que se manifesta na construção de um mundo possível”. Assim, a notícia é construída pelo jornalista como um mundo possível, ao se utilizar dos esquemas interpretativos do mundo de referência para dar sentido ao mundo real dos acontecimentos. O inter-relacionamento dos três mundos fica evidente na afirmação de que o mundo possível em que se constitui a notícia será construído pelo jornalista levando em conta o mundo real e um mundo de referência escolhido.

Em resumo, o jornalista não pode estabelecer qualquer mundo possível, mas precisa levar em conta os fatos que ele conhece sobre o assunto que pretende relatar e as características do mundo de referência a que os fatos remetem. Esse mundo possível construído dessa forma terá as marcas pertinentes do mundo de referência (ALSINA, 2009, p. 308).

Nas três esferas do jornalismo analisadas por Daniel Hallin (1986 apud TRAQUINA, 2004, p.114), a esfera do consenso compreende a grande maioria das matérias elaboradas sob a égide do pensamento único, uma vez que os jornalistas não se sentem obrigados, diante do consenso social estabelecido pelo discurso ideológico dominante, de apresentarem as versões dissensuais, contra-hegemônicas ou contrafactuais. Desta maneira, o consenso a que Hallin se refere é elaborado, sob a influência do discurso ideológico hegemônico, nas interações simbólicas da vida social e não na forma como se dá o processo de construção de sentidos, identidades e decisões operada na discussão pública articulada pela mídia noticiosa.

Nesta construção, numa análise baseada na pragmática universal de Habermas, o debate torna-se refém de uma "teia de facticidade" e é esvaziado com a exclusão dos posicionamentos que se distanciam do consenso social (TUCHMAN, 1999). Ocorre, então, o seu deslocamento para a esfera do desvio, que fica assim hipertrofiada tanto quanto a ilegitimidade do "consenso" produzido na dita esfera do consenso, que, assim, seria melhor denominada de esfera do "pseudo-consenso" (HABERMAS, 1984).

A esfera da controvérsia legítima, o grande ideal comunicativo da teoria democrática, por fim, fica reduzida a uma dimensão extremamente restrita, diante da prevalência da teoria do espelho, que considera o compromisso do jornalismo com a 
diversidade significativa existente na sociedade uma fraqueza devido à sua presunção de apresentar a verdade absoluta dos fatos, relegando o debate pluralista àquelas situações em que não pode esconder as dúvidas sempre existentes sobre a realidade.

A classificação de Hallin, em grande medida, corresponde à concepção de Habermas das três formas de deliberação na esfera pública: o modelo de acesso interno nas tomadas de decisão na discussão pública articulada pela mídia equivale à esfera do consenso (ou pseudo-consenso) de Hallin, uma vez que o resultado das questões tratadas pela mídia noticiosa fica determinado pela lógica interna da estrutura de poder, sistematicamente omitindo os movimentos sociais e os setores menos favorecidos, que formam a periferia do sistema.

Segundo Daniel Hallin (1994, p. 30), Habermas tem razão quando aponta a impossibilidade da estrutura de poder construir sentido intersubjetivamente compartilhado. Daí a eventualidade dos jornalistas conseguirem furar o determinismo das políticas editorias dos veículos pautando temas inconvenientes à estrutura de poder. Isto acontece quando o monopólio da estrutura de poder (fontes oficiais) no acesso à visibilidade do espaço público é quebrado pela ação de um jornalista, que abre uma brecha e expande a política editorial da empresa onde trabalha, ou por pressão dos movimentos sociais.

Então, verifica-se o modelo de mobilização, em que a tomada de decisão nos assuntos depende do veredicto das "galerias da opinião pública" e não mais está refém da lógica interna da estrutura de poder, o que pode ser entendido como similar à controvérsia legítima de Hallin. Porém, ainda neste caso, o resultado das questões, geralmente, beneficia os interesses particulares poderosos do sistema, que detêm o aparelho de estado e o poder econômico das corporações do mercado para cooptar apoios e mobilizar adesões.

Contudo, em situações de crise, acontece dos movimentos sociais, não só conseguirem institucionalizar na pauta jornalística temas que a estrutura de poder gostaria de manter engavetados, configurando o modelo de mobilização, mas também obter solidariedade suficiente para formar opinião e vontade política como poder comunicativo capaz de obrigar o Legislativo a elaborar leis que contemplem seus 
direitos, como também o Judiciário e o Executivo a cumprirem estas leis. Estes casos representam o modelo de iniciativa externa.

$\mathrm{Na}$ defesa da eventualidade desta possibilidade, Hallin (1995, p. 11) aponta o fato da estrutura de poder apresentar divisões entre os grupos de elite que a compõem que viabilizam ao jornalismo a expansão da controvérsia legítima. No mesmo sentido registra a existência de contradições entre o interesse de estabilização do sistema e a necessidade econômica da mídia noticiosa de aumentar a sua representatividade e legitimidade diante do seu público, para valorizar o seu espaço comercial (HALLIN, 1995, p. 32).

Por fim, evidencia-se a tensão decorrente da dupla identidade social da mídia noticiosa de se constituir em empresa comercial e, ao mesmo, tempo, numa instituição cultural de produção de sentidos (HALLIN, p. 34). Este fato explica a existência da permanente, complexa e imbricada tensão entre os interesses comerciais da empresa e a sua função social. Neste contexto, o desempenho do jornalista depende da construção de um acervo de conhecimento de excelência profissional que o habilite a perceber as contradições internas da estrutura de poder, entre esta e os interesses comerciais da empresa jornalística e ainda entre as aspirações instrumentais do veículo e a demanda por sentido e legitimidade da sociedade.

Afinal, contra a barbárie obscurantista, cuja síntese maior é a máxima 'manda quem pode, obedece quem tem juízo', com a qual se pretende menosprezar a grande busca humana para conferir sentido à vida, o compromisso essencial do jornalismo é combater, mais do que o non sense, a negação da possibilidade de se fazer a vida ter sentido e, por conseguinte, concretizar o ideal, sempre aproximativo e nunca completo, da liberdade, pois, como observa Tzvetan Todorov (2000, p. 20), "o sentido é liberdade e a interpretação é o seu exercício".

Assim, o profissional deve perceber que a sua lealdade maior, para conquista de um conceito de excelência profissional, é com a objetividade do que é intersubjetivamente reconhecido como válido e faz sentido para o maior número de cidadãos de seu auditório, mas também que leve em conta que ele é composto por pessoas em processo de aprendizagem. Isto implica numa concepção de "verdade normativa" de postura pós-convencional, que contemple não só o que está 
convencionado no consenso social, mas também as aspirações dissensuais, contrahegemônicas e contra-factuais que almejam a construção de uma sociedade com potenciais menores de conflito e violência e, conseqüentemente, com uma vida menos ameaçada e mais autêntica.

\section{Referências Bibliográficas}

ALSINA, Miquel Rodrigo. A construção da notícia. Petrópolis: Vozes, 2009.

BERGER, Peter; LUCKMANN, Thomas. A construção social da realidade. Petrópolis: Vozes, 1995.

HABERMAS, Jürgem. A ética da discussão e a questão da verdade. São Paulo: Martins Fontes, 2004a.

. Direito e Democracia: entre facticidade e validade. Rio de Janeiro: Tempo Brasileiro, v. II, 1997.

. Mudança estrutural da esfera pública. Rio de Janeiro: Tempo Brasileiro, 1984.

. Verdade e justificação. São Paulo: Edições Loyola, 2004b.

HALLIN, Daniel C. We keep America on top of the world: television journalism and the public sphere.London/New York: Routledge, 1994.

KUHN, Thomas. A estrutura das revoluções científicas. São Paulo: Perspectiva, 2007.

MEDITSCH, Eduardo. O jornalismo é uma forma de conhecimento? In: GOBBI, Maria Cristina; HOHLFELDT, Antonio. Teoria da comunicação: antologia de pesquisadores brasileiros. Porto Alegre: Sulina, 2007.

PARK, Robert. A notícia como forma de conhecimento: um capítulo dentro da sociologia do conhecimento. In: BERGER, Christa; MAROCCO, Beatriz. A era glacial do jornalismo. Porto Alegre: Sulina, 2008.

PEREIRA JR., Alfredo Eurico Vizeu. Decidindo o que é notícia. Porto Alegre: EDIPURCRS, 2001. RORTY, Richard. Pragmatismo, filosofia analítica e ciência. In: PINTO, Paulo Roberto Margutti et all. (Orgs). Filosofia analítica, pragmatismo e ciência. Belo Horizonte: Ed. UFMG, 1998.

TRAQUINA, Nelson. A tribo jornalística: uma comunidade transnacional. Lisboa: Editorial Notícias, 2004.

TODOROV, Tzvetan. Prefácio. In: BAKHTIN, Mikhail. Estética da criação verbal. São Paulo: Martins Fontes, 2000.

TUCHMAN, Gaye. A objetividade como ritual estratégico. In: TRAQUINA, Nelson. Jornalismo: questões, teorias e "estórias". Lisboa: Vega Editora, 1999.

VAN DIJK, Teun A. Notícias e conhecimento. Revista Estudos em Jornalismo e Mídia - v. II, $\mathrm{n}^{\circ} 2,2^{\circ}$ Semestre de 2005 - Revista Acadêmica Semestral - Programa de Pós-Graduação em Jornalismo e Mídia da Universidade Federal de Santa Catarina.

Este artigo e todo o conteúdo da Estudos em Jornalismo e Mídia estão disponíveis em http://www.periodicos.ufsc.br/index.php/jornalismo/index

Estudos em Jornalismo e Mídia está sob a Licença Creative Commons. 